\title{
Screening for Oral Cancer 2018
}

\author{
L. Döbrőssy¹, K. Lapis² \\ ${ }^{1}$ Office of Chief Medical Officer, Budapest, Hungary \\ ${ }^{2}$ Pathological and Experimental Cancer Research Institute, Semmelweis University, Budapest, Hungary \\ Email: dobrossy.lajos@oth.antsz.hu
}

How to cite this paper: Döbrössy, L. and Lapis, K. (2018) Screening for Oral Cancer 2018. Journal of Cancer Therapy, 9, 465-479. https://doi.org/10.4236/jct.2018.96039

Received: March 14, 2018

Accepted: June 2, 2018

Published: June 5, 2018

Copyright (ㅇ 2018 by authors and Scientific Research Publishing Inc. This work is licensed under the Creative Commons Attribution International License (CC BY 4.0).

http://creativecommons.org/licenses/by/4.0/

\begin{abstract}
In Hungary, the incidence and mortality from oral cancer is so high, that in the past decades it has attracted international attention. The mortality rates are the highest in Europe. As risk factors, smoking and alcohol drinking have a multiplicative role; in addition, a number of dental factors also play a role. Premalignant conditions and lesions are well known. They should be targeted for early detection and early treatment. The screening tool is simple: inspection and palpation. The physician-patient encounters provide opportunity for screening. This paper looks for the answer to the long debated question: who is responsible for oral screening?
\end{abstract}

\section{Keywords}

Oral Cancer, Premalignant Lesions, Early Detection by Screening

\section{Introduction}

"Oral cancer" is a collective term. The International Classification of Diseases (ICD-O) lists under this heading the tumors of the lips, oral cavity, the pharynx, and the not otherwise specified anatomical sites of the oral cavity (C00-C14), with the exception of the malignant tumors of the parotid gland (C07), major salivary glands (C08), tonsils (C09) the sinuses (C31) and the larynx (C32). In this paper, we are dealing with those tumors that are traditionally referred to as "cancers of the oral cavity". It is justified to discuss these as the same group of cancers because $\left.{ }^{*}\right)$ "oral cancers" arising in mucous membranes of the mouth (i.e. lip. the base of, tongue, gum, floor of mouth and plate, and other unspecified parts of mouth) and pharynx (comprising the oropharynx, hypopharynx and nasophasynx) are squamous cancer of various degrees of differentiation; $\left({ }^{*}\right)$ the same risk factors play a role in their development; $\left(^{*}\right)$ they have a lot in common in the natural history and course of these diseases; and $\left(^{*}\right)$ due to their 
anatomical site they are easily accessible for early detection and early treatment, therefore they lend themselves to screening.

\section{Epidemiology}

In 2012, according to the World Cancer report, 530.000 new oral cancer cases were diagnosed, and 290.000 deaths were registered world-wide. Two-thirds of new cases are reported from the low-, and lower-middle income countries [1]. In 2004, there were 67,000 new cases registered in the countries of the European Union (EU). Overall in the EU, oral and pharyngeal cancer occupies the $7^{\text {th }}$ position. Within the EU countries the highest male incidence rates are found in Hungary (29 per 100.000), and the lowest rates are found in Greece (4 per 100.000). In one report the rate for oral cancer in men in France was almost seven times greater than that for men in Greece. The differences among the countries might be twenty-fold. In Europe, oral cancers are the most common in Easter European countries from where the highest mortality rates are reported [2]. Of those suffering from oral cancer, $80 \%$ could hardly survive one year after the clinical diagnosis [3]. Five-year survival is reported only from clinical centers where best treatment can be provided [4].

Mortality rates show major changes over time. It is most striking in Central and Eastern Europe, where there has been approximately a doubling in death from oral cancer. Dramatic rising trends are reported from Hungary. In this country, the mortality from oral cancer has been the highest in the European countries. According to the Central Statistical Office, between 1948 and 2004 the all cancer mortality increased by 2.8 fold, but the mortality from oral cancer increased by 6.8 fold [5]. Incidence of oral cancer peaked in 2000, and since then it has been stagnating at a high level.

\section{Risk Factors}

According to the definition of classical epidemiology, the "cause of a disease" is a factor which is necessary and, at the same time, sufficient to develop a disease. As a contrast to the infectious diseases, the causes of cancer, that of the causes of oral cancer, in particular, are not sufficiently understood. Epidemiological evidence, however, has suggested that many different factors are not necessarily causal agents but are associated, individually or in combination, with an increased probability, or risk of the occurrence of these cancers. These factors are named as "risk factors".

In the case of oral cancers, the majority of risk factors are lifestyle-dependent. In this context, lifestyle is defined as "as a set of personal decisions on which the individual has more or less influence" [6].

\subsection{Tobacco and Drinking}

In the development of oral cancers the physical-chemical irritation of tobacco smoking and heavy alcohol consumption are well established risk factors. The 
most comprehensive sources of epidemiological evidence are available in the IARC publications on the subject [7] [8] [9]. Each factor alone may account for a two- to three-fold increase in risk, however, risk for cancer of oral cavity increases multiplicatively in relation to the respective risk generated to either exposure in the absence of the other: when tobacco and alcohol consumption are combined, they may increase the risk by more than 15-fold [10] [11]. Heavy smoker and drinkers have a 100-time as high risk as compared to those who have never smoked and consumed alcohol [12]. It has been estimated that approximately $60 \%$ of oral cancer in men and $30 \%$ in women could be attributed to smoking alone [13].

The evidence relating to certain dietary components and the risk of cancer is inconsistent. Dietary deficiencies or imbalances may also play a causative role as high as $10 \%-15 \%$ of cases [14]. Micronutrient deficiencies seem to be associated with increased risk [15]. At the same time, evidence that a diet high in vegetables (particularly reach in carotenes) and fruit products decreases the risk is rather convincing [16].

\subsection{Dental Factors}

Chronic mucosal trauma resulting from sharp teeth, dentures, poor oral hygiene, unhealthy diet, or implants has frequently been associated with the development of oral cancer [17]. Some studies indicate that poor oral hygiene may act synergistically with some other risk factors such as alcohol in a way that acetaldehyde-production in the saliva increased, and this metabolite of ethanol constitutes the real carcinogenic risk [18]. However, as these are confounded by socioeconomic factors, caution is required to evaluate the importance of dental factors.

\subsection{Human Papillomavirus (HPV)}

Recently, several studies have investigated the prevalence of HPV in oral cancers. The possible causal role of HPV was first indicated by Gillison and co-workers, [19] [20], the association was later proved by polymerase chain reaction (PRC) and in situ hybridisation [21]. The oral HPV is sexually transmitted, and in our time, the changes of sexual behavior can provide an explanation for the increased number of oropharyngeal cancers in the developed countries [19]. However, the transmission of HPV in the oral cavity requires further studies [20]. It appears that the HPV-positive oral cancers represent a particular clinico-pathological entity the association of which, with the smoking habit and alcohol consumption, is less characteristic; the prognosis of this subset seems to be more favorable as compared with their HPV-negative counterparts [21] [22].

\subsection{Socioeconomic Status}

Oral cancers are more prevalent in lower socioeconomic groups of the population [23]. 


\section{Natural History Precoursors}

In general, "precursor", or premalignant lesion means a condition preceding the pathological onset of cancer. It has no necessarily causal relationship with cancer; notwithstanding, it is considered as an indicator of the increased risk for cancer development.

In stomatology, precancerous conditions and precancerous lesions are distinguished [24] [25]. The former are oral manifestation of a global condition (e.g. iron deficient anemia, lichen oris, lupus erythematodes etc.). More important are the precancerous lesions which mean morphologically altered tissues in which cancer is more likely to occur than in the apparently normal counterparts. Such a lesion is the leukoplakia and erythroplakia, the classification of which was first described by Bánóczy [26] [27]. Their rather loose definitions are descriptive one, and do not mean pathological entities. In 1978, a World Health Organization Working Group defined oral leukopalakia as "a white path or plaque that cannot be characterized histologically and clinically, as any other disease" [24], and, "is not associated with any physical or chemical agent except the use of tobacco" [28]. Histologically, these are hyperkeratotic areas with some degree of dysplasia of the cells, therefore, they are considered as having increased risk of becoming malignant [29].

\section{What Can Be Done to Alleviate the Burden of Oral Cancers?}

According to the state-of-the-art of medical and other related sciences, the most promising strategy for alleviating the burden of oral cancer are disease prevention in the long run, and screening in short- and medium term.

With regards to primary prevention, there are plenty of opportunities for primary prevention, i.e. for the prevention of cancer from developing, by eliminating the risk factors, most of which are lifestyle-dependent, by means of health education and regulatory measures. Nevertheless, reducing incidence through primary preventive program and by health promoting measures is likely to be a long-term undertaking, and is not promising anyway as "bad habits die hard". According to educated guesses, in such a way, the incidence of oral cancers might be reduced by some $60 \%-80 \%$. When primary prevention fails, early detection through screening and relatively inexpensive treatment can avert most deaths.

\section{Early Detection by Screening}

The target-population of screening is the healthy or apparently healthy persons who consider themselves healthy but, in fact, they are sick for some latent, symptomless disease. The rationale for screening is that oral cancer may be preceded by a clinically detectable potentially malignant lesion (leukoplakia or erythroplakia) or that it may begin as a small, localized, often asymptomatic lesion in the early part of its natural history The target condition of screening is 
any risk factor that has a role to play in developing a disease, any premalignant lesions that proceed the disease, or an early stage cancer.

The main purpose of screening is to rule out or to raise the probability of some disease. Screening methods are not suitable for establishing a final diagnosis; that is the task of a clinical procedure which needs to follow the screening. Thanks to screening, the treatment might start much earlier than it would have happened without screening. Thus, it is fair to say that screening might improve both the life expectancy and quality of life of those who attend it.

The earlier detection of a disease followed by early treatment might prevent the fatal outcome. Screening of a high risk population might detect of a significant number of oral cancers, most of them still in a stage suitable for treatment [30]. According to meta-analysis of great number of publications, inspection and palpation are the screening methods at hand.

\subsection{Methods of Oral Screening}

Thanks to their anatomical location, the pathologies of oral cavity can be seen by the naked eye, and palpated by hands; therefore, the screening tools for oral screening are simple: inspection and palpation [31]. At screening, a few questions need to be raised about the smoking and drinking habits. Following that, the lips, oral cavity, the buccal mucosa, the gum, the upper and lower surface of the tongue, the hard and soft palate, as well as the pharynx need to be carefully examined. Finally, the cervical and sublingual lymph nodes are palpated [32]. If any suspicion arises, biopsy for histological examination needs to be done. In clinical practice, there are some diagnostic aids to be used as CT and MRI [33], toluidine blue staining [34], fluorescence imaging techniques [35], brush-biopsy for cytology [36].

\subsection{Organized and Opportunistic Screening}

As is widely known, there are two screening models used in the health care system: organized and opportunistic ones [27] [37]. By definition, organized screening means provider-initiated, centrally financed screening where the target population, i.e. asymptomatic persons at high risk by age are individually identified, and personally invited by a letter in which the time and site of the screening are indicated, and, the screened persons are individually followed up; opportunistic screening is a public health measure. On the other hand, opportunistic screening can take place at any physician-patient encounter; it depends only on the physician's judgment and "oncological alertness", as well as on the patient's request. On the contrary, organized screening must be of proven effectiveness, in term of reduction of mortality from the target population attributable to the screening [38]. According to the international convention, the effectiveness of a screening modality must be established in randomized controlled trials. Up to now, there have been three screening modalities meeting these criteria: cervical screening by cytology [39], breast screening by mammography 
[40], and colorectal screening by the detection of occult blood in the stool [41]. These three screening modalities are being encouraged by the recommendations of the international organization, such as the Council of the European Union to implement as organized screening program on national scale.

\subsection{Organized Screening for Oral Cancer?}

Up until now, there is only one properly conducted randomized controlled trial that has used mortality as the primary outcome. This oral cancer screening trial was a community-based cluster-randomized control trial carried out in North Trivandrum, Kerala, India from 1996-2008, where in 7 regions randomizes trials had been carried out, and another 6 regions served as controls. In the screened population, inspection by trained personnel every three years was the screening tool. In the twelve year follow-up, 138 deaths from oral cancer (14.4/100.000) in the screened arm, and 154 cases (17.1/100.000) in the control group was reported [42] [43]. However, impartial judges do not consider the results as statistically significant [44].

Several large population screening programs from developing and smaller studies from developed countries had been reported over the years, but all failed to provide evidence of effectiveness, in term of mortality reduction [45]. For low-risk populations, the UK Working Group on Screening for Oral Cancer and Precancer concluded that there was insufficient evidence to support population screening [46] [47]. According to the prestigious US Preventive Services Task force, the evidence is insufficient to make any recommendations [48]. Similar positions are taken by other professional organizations, such as the American Cancer Society, the American Dental Association Council, and others [45].

Some of the obstacles include the relative rarity of the disease, a lack of knowledge of the natural history of the disease, disagreement over disease management and the lack of evidence on the efficacy and cost-effectiveness of different screening methods [49]. One can conclude that the organized population screening for oral cancer is not feasible.

\subsection{Opportunistic Screening for Oral Cancer}

Opportunistic screening for oral cancer and precancer in general dental practice is a realistic alternative to population screening, as patients attending the practice are representative of the general population, both in terms of lesion prevalence and high risk habits such as smoking and drinking. The study of Lim et al demonstrates that opportunistic screening for oral cancers by general dentists is feasible and worthwhile [50]. Here, opportunistic screening means examining patients who are at high risk for oral cancer because of risky habits. This study demonstrates that the prevalence of positive lesions is consistent with the general population prevalence and that the dental attendees mimicked the general pattern. However, dental schools have placed little emphasis on oral cancer prevention and early detection, especially compared with other content areas such 
as restorative and prosthetic dentistry. Not surprisingly, general dentists have essentially ignored detection of these cancers. Equally unsurprising, most oral cancers are detected at a late stage and, as a result, five-year survival rates are among the lowest for all major cancers. Several other authors argue that receiving regular dental examinations at least annually may reduce the public health burden of oral and pharyngeal cancer by facilitating earlier detection of the disease [51].

Although the blame for the detection of early oral cancer and its precursors is passed to the general dental practice, experience shows that if every patient attending the dental practice would be carefully screened, the opportunistic oral screening would not bring the desired results, and would not be cost-effective [52].

Some argue that those persons at highest risk for oral cancers do not seek dental services. In fact, low socioeconomic status is significantly associated with increased oral cancer risk in high and lower income-countries, across the world, and remained so when adjusting for potential behavioral confounders. Inequalities persist but have perhaps been decreasing over recent decades. Oral cancer risk associated with low socioeconomic status is significant and comparable to lifestyle risk factors [53]. Most of the high risk persons and oral cancer patients are over 40 years of age, cumulatively disadvantaged, heavy smokers and alcohol drinkers, neglecting oral hygiene, or homeless who avoid the dental clinic [54]. Selective screening of these high risk individuals of the low social-economic subgroup should be a priority for the health care system. However, it is a difficult task.

Of all health providers, general dentists are the most logical group to perform screening for these cancers. However, individuals who are at greatest risk rarely visit a dentist; they are more likely to consult general medical practitioners. Therefore, they could have an important role in the early detection of oral cancer. Research has shown that general practitioners do not opportunistically screen high-risk individuals; however, the barriers to screening are poorly understood [55].

The educational needs of primary care-givers including dentists, and general practitioners must be addressed and the difficulty of reaching high-risk groups is still there [56]!

\section{Discussion}

Oral cancers are an increasing public health problem. At present, most of the oral cancer patient turns to a doctor at a late, advanced, neglected state when the tumor is already incurable [57]. This is why the survival time of diagnosed oral cancer is very low, and the mortality rates are extremely high. Life expectancy depends on early detection and early treatment [58]. Early detection through screening, therefore, is a crucial issue [59] [60]. Health education campaigns can temporarily attract the attention of the population to screening but public inter- 
est soon subsides. The integration of oral screening into the practice of general dentists and general practitioners seems to remain under the desired level. In exceptional cases, early stage cancer is seen by the dentist; the general practitioner's task is to "cure the incurable". Delay in the diagnosis of oral cancers is common; up to half of all patients are diagnosed with advanced lesions, thus it is essential to develop methods to aid early detection [61]. The association of social-economic-educational status and development of cancer receive more and more attention in the sociological and epidemiological literature: the inequalities of health are known to reflect social inequalities [62]. The majority of oral cancer patients are economically disadvantaged. Their chance to survive is more unfavorable than the average, they show excess mortality. Those who live on the "sunny side" of society, having higher education, are more aware of the risks of oral cancer, and are more ready to attend screening, as compared to those in the "shady side", notwithstanding that the latter is at higher risk for oral cancer.

Several reviews examine whether oral cancer risk is associated with low socio-economic status. In a meta-analysis by Warnakulasuriya, four out of the 37 studies provided data on the association of education with oral cancer risk, and concluded that high educational levels were associated with an increased risk for oral cancer [63]. However, higher educated individuals are more likely to be aware of, and screened for, oral cancer. This is problematic because oral cancers are more prevalent in low socio-economic groups.

Analyses have shown that low socioeconomic status was significantly associated with increased oral cancer risk in high and lower income-countries, across the world, and remained so when adjusting for potential behavioral confounders. Inequalities persist but have perhaps been reduced in recent decades. Oral cancer risk associated with low socioeconomic status is significant and comparable to lifestyle risk factors. The results provide evidence to steer health policy which focus on lifestyles factors toward an integrated approach incorporating measures designed to tackle the root causes of disadvantage [64].

The association between human behavior patterns and the development of oral cancer is widely recognized. Most oral cancer cases and deaths are due tothe exposure to carcinogens caused by lifestyle behaviors such as tobacco smoking, betel liquid or tobacco chewing, alcohol intake, and micronutrient deficiencies. The purpose of the reviews is to provide insights into the social and behavioral factors associated with the development of oral cancer. These lifestyle factors and behaviors are considered the downstream determinants of oral cancer, while the upstream determinants are those which are common to all cancers such as the community level environmental factors, industrial pollution and contamination, access to the health care system, health insurance, and quality of health care, which are all dependent on the socioeconomic status of the individual. It was concluded that, since the incidence of oral cancer is greatly impacted by behaviors that can be modified, the impact that these behaviors-as well as other social determinants-have on oral cancer and its outcome needs to be addressed by society. The more vulnerable patients seem generally unaware of the risk of 
oral cancer screening or are reluctant to accept the offered screening; therefore, future awareness and screening effort should be directed at the yearly screening of higher risk, more vulnerable populations [65].

1) Who is responsible for oral screening?

The question to be answered: who is responsible for oral screening, and whose task is it? No doubt, primarily, oral screening should be the task of general dental practices, but most of the dentists do not pay sufficient attention to the prevention of the oral precancer (leukoplakia, erythroplakia) and cancers, and to their detection in a complaint-free state-in spite of the fact that, in most countries, there are regulations making the stomato-oncological screening of their patients mandatory [66]. Dentists in private practice are particularly reluctant to screen.

Most general dental practitioners were adequately aware of oral screening and biopsy procedures but felt reluctant to perform them, which suggests that dental education programmes are needed for them in oral pre-cancer/cancer detection as well as screening and diagnostic procedures.

The dental hygienist is a primary resource for oral cancer screening and prevention. In more and more countries, there is regular education and training for "dental hygienists" or "oral hygienists" through dental schools or universities [67]. They are licensed as dental professionals, registered with a dental association, or a regulatory body within their country of practice. They are primary healthcare professionals who work independently of, or alongside, dentists and other dental professionals to provide full oral health care. They have the training and education that focus on and specialize in the prevention of oral diseases. Most importantly, they spend a large amount of time at each patient visit looking at the soft tissues of the oral cavity, where the early manifestations of oral cancer occur [68].

Primary care physicians are well suited to providing examinations of oral cancer, and to screening for the presence of suspicious oral lesions, and referral of suspicious patients to specialists for biopsy could be expected from them. However, they generally do not regard oral screening as their task.

In a study investigating the symptoms associated with cancer of the oral cavity and exploring the role of general practitioners in the identification and referral of patients, a questionnaire was sent to 200 patients on the route to diagnosis, symptoms, delay in presentation, and outcomes of consultations with their general practitioner. Of 161 respondents, over half (56\%) had been referred to secondary care by their general practitioner, and one-third (32\%) by their dentist. The most commonly reported symptoms were a mouth ulcer (32\%), a lump in the face or neck (28\%), and pain or soreness in the mouth or throat (27\%). Fifteen per cent delayed presentation for more than 3 months. After consultation with a general practitioner, $(\mathrm{n}=109), 53 \%$ were referred to a specialist, $22 \%$ were referred for tests, $12 \%$ were told that their symptom was not serious, and $12 \%$ were treated for another condition. General practitioners have an important role in the identification and referral of people with oral cancer, and the clearly 
recognized symptoms identified in this study can be used to aid assessment and decision-making. Interventions to promote the prompt identification of oral cancer in general practice such as the opportunistic screening of high-risk patients may help to improve the poor survival rates [69].

2) Attempts to screen

In Hungary, the burden of the disease is high, the highest in Europe, therefore screening for oral cancer is a major issue. During the past decades, zealousstomatologists conducted several opportunistic stomato-oncological screening campaigns; the summary of these was published Bánóczy et al. Out of some 20.000 examinations $0.12 \%$ oral cancer and $2.63 \%$ precancerous lesions were detected [70]. In another case, 300 heavy smokers and drinkers were examined, and 43 premalignant lesions (14.33\%), and 8 histologically verified oral cancers (2.66\%) were verified [71]. In summary, they found lesions worth of medical attention in one-fifth of the cases.

Unfortunately, the target population of oral screening is not "regular" for either the dental or the general practitioner' office. It is estimated that about half of the population regularly visit a general dental practice, most of them only in case of toothache; three-fourth of patients with leukoplakia go to the doctor, but only with complaints [72]. Most of the high risk persons would be found in pubs or homeless shelters; they are heavy smokers and regular drinkers, socially disadvantaged, unemployed, who go to doctors only in an advanced, hopeless state. In such patients both the dentist and general practitioners are totally helpless.

\section{What to Do?}

1) The average population is unaware of the risk factors and early signs of oral cancer, therefore health care personnel's task is to provide all information, and to encourage people to see a doctor if they have any complaints indicating any oral disorders. This is a challenge for health education. In the message of health education, the information on the importance and availability of oral screening, as well as the possible role of HPV in the development of the oral cancer, all needs to receive greater emphasis.

2) One must strive for an annual screening of high-risk individuals. In order to reach them, cooperation has to be established with those authorities and non-governmental (civil) organizations whose task is to take care of the disadvantaged persons.

3) In undergraduate and postgraduate education and training of dentists, dental hygienist, physicians, and general practitioners, in particular, a major emphasis has to be given to the risk factors and early signs, the prevention and screening of oral cancer.

\section{Epilogue}

Oral cancer-due to its frequency and role in cancer mortality-is a major public health problem. The majority of oral cancers are discovered at an advanced 
stage; the ratio of advanced cases has not decreased in the last 40 years. The knowledge and opportunities of primary prevention and early detection or screening is not sufficiently applied; this is one of the "plague-spots" of health care in most countries; something must be done about it. If those in the general dental practice and primary care would apply themselves to the task more, the decrease of the burden of oral cancer on society would become a realistic goal.

\section{References}

[1] Stewart, B.V. and Christopher, P.W. (eds) (2014) World Cancer Report 2014. WHO, Geneva.

[2] Warnakulasuriya, S. (2009) Global Epidemiology of Oral and Oropharyngeal Cancer. Oral Oncology, 45, 309-316. https://doi.org/10.1016/j.oraloncology.2008.06.002

[3] American Cancer Society (2004) Cancer Facts \& Figures 2004. American Cancer Society, Atlanta.

[4] Johnson, N.W., Warnakulasuriya, S., Gupta, P.C., Dimba, E., Chindia, M., Otoh, E.C., Sankaranarayanan, R., Califano, J. and Kowalski, L. (2011) Global Oral Health Inequalities in Incidence and Outcomes for Oral Cancer: Causes and Solutions. Advances in Dental Research, 23, 237-46.

https://doi.org/10.1177/0022034511402082

[5] Döbrőssy, L. (2005) Epidemiology of Head and Neck Cancers. Cancer and Metastasis Reviews, 24, 9-16. https://doi.org/10.1007/s10555-005-5044-4

[6] Lalond, M. (1974) A New Perspective on the Health of Canadians. A Working Document, Information Canada.

[7] International Agency on Research for Cancer: Tobacco Smoking (1986) IARC Monograph on the Evaluation of the Carcinogenic Risk of Chemicals to Humans. IARC, Lyon, Vol. 38.

[8] Tomatis, L. (1990) (szerk): Cancer: Causes, Occurance and Control. IARC. Science Publication, IARC, Lyon, No. 100.

[9] International Agency on Research for Cancer IARC (1996) Cancer in the European Union in 1990. IARC, Lyon.

[10] Tuyn, A.J., Esteve, J., Raymond, I., Berrino, F., Benhamou, E., Blanchet, F., Boffetta, P., Crosignani, P., del Moral, A., Lehmann, W., et al. (1988) Cancer of Larynx/Hypopharynx, Tocaccoand Alcohol. IARC International Case-Control Study in Turin and Varese (Italy), Zaragosa and Novarra (Spain), Geneve (Switzer L, Berrino F, Benhamou E, Blanchet F, Boffetta P, Crosignani P, del Moral A, Lehmann $\mathrm{W}$, and) and Calvados (France). International Journal of Cancer, 41, 489-491.

[11] Morse, D.E., Psoter, W.J., Cleveland, D., Cohen, D., Mohit-Tabatabai, M., Kosis, D.L. and Eisenberg (2007) Smoking and Drinking in Relation to Oral Cancer and Oral Epithelial Dysplasia. Cancer Couses Control, 18, 919-929. https://doi.org/10.1007/s10552-007-9026-4

[12] Zheng, T. and Boyle, P. (2004) Tobacco Use and Risk of Oral Cancer. In: Boyle, P., Gray, N., Henningfield, J., Seffrin, J. and Zatonski, W., Eds., Tobacco: Science, Policy and Public Health, Oxford University Press, Oxford, 399-432.

[13] Shield, K.D., Ferlay, J. and Jemal, A. (2017) The Global Incidence of Lip, Oral Cavity, and Pharyngeal Cancers by Subsite in 2012. CA: A Cancer Journal for Clinicians, 67, 51-64.

[14] Meurman, J.H. (2010) Infectious and Dietary Risk Factors of Oral Cancer. Oral 
Oncology, 46, 411-413. https://doi.org/10.1016/j.oraloncology.2010.03.003

[15] Richie, J.P.Jr., Kleinman, W. and Marina, P. (2008) Blood Iron, Glutathione, and Micronutrient Levels and the Risk of Oral Cancer. Nutrition and Cancer, 60, 474-482. https://doi.org/10.1080/01635580801956477

[16] Boeing, H., Bechthold, A. and Bub, A. (2012) Critical Review: Vegetables and Fruit in the Prevention of Chronic Diseases. European Journal of Nutrition, 51, 637-663.

[17] Singhvi, H.R., Malik, A. and Chaturvedi, P. (2017) The Role of Chronic Mucosal Trauma in Oral Cancer: A Review of Literature. Indian Journal of Medical and Paediatric Oncology, 38, 44-50.

[18] Hofmann, T., Tillonen, J., Pitmaki, H., Salaspuro, M., Lindqvist, C. and Meurman, J.H. (2001) Poor Dental Status Increases Acetaldehyd-Production from Etanol in Saliva: A Possible Link to Increased Oral Cancer Risk in Heavy Drinkers. Oral Cancer, 37, 153-158.

[19] Gillison, M.L., Koch, W.M., Capone, R.B., Spafford, M., Westra, W.H., Wu, L., Zahurak, M.L., Daniel, R.W., Viglione, M., Symer, D.E., Shah, K.V. and Sidransky, D. (2000) Evidence for a Causal Association between Human Papillomavirus and a Subset of Head and Neck Cancers. National Cancer Institute, 92, 709-720. https://doi.org/10.1093/jnci/92.9.709

[20] Gillison, M.L. (2004) Human Papillomavirus-Associated Head and Neck Cancer Is a Distinct Epidemiologic, Clinical, and Molecular Entity. Seminars in Oncology, 31, 744-754. https://doi.org/10.1053/j.seminoncol.2004.09.011

[21] Singhi, A.D., Westra, W.H., Spafford, M., Westra, W.H., Wu, L., Zahurak, M.L., Daniel, R.W., Viglione, M., Symer, D.E., Shah, K.V. and Sidransky, D. (2010) Comparison of Human Papillomavirus in Situ Hybridization and p16 Immunohistochemistry in the Detection of Human Papillomavirus-Associated Head and Neck Cancer Based on a Prospective Clinical Experience. Cancer, 116, 2166-2173.

[22] Elrefaey, S., Massaro, M.A., Chiocca, S., Chiesa, F. and Ansarin, M. (2014) Review HPV in Oropharyngeal Cancer: The Basics to Know in Clinical Practice. Acta Otorhinolaryngologica Italica, 34, 299-309.

[23] Johnson, S., McDonald, J.T. and Corsten, M. (2012) Oral Cancer Screening and Socioeconomic Status. Journal of Otolaryngology_Head \& Neck Surgery, 41, 102-107.

[24] WHO Collaborating Centre for Oral Precancerosus Lesions (1974) Definition of Leukoplakia and Related Lesions. Oral Surgery, Oral Medicine, Oral Pathology, Oral Radiology, 46, 518-539.

[25] Axell, T., Holmstrup, P. and Kramer, I.P.H. (1984) International Seminar on Oral Leukoplakia and Associated Lesion Related to Smoking Habit. Community Dentistry and Oral Epidemiology, 12, 145-154. https://doi.org/10.1111/j.1600-0528.1984.tb01428.x

[26] Bánóczy, J. (1982) Oral Leukoplakia. Akadémiai Kiadó. Budapest. 64-86.

[27] Warnakulasuriya, S., Johnson, N.W. and van der Waal, I. (2007) Nomenclature and Classification of Potentially Malignant Disorders of the Oral Mucosa. Journal of Oral Pathology \& Medicine, 36, 575-580. https://doi.org/10.1111/j.1600-0714.2007.00582.x

[28] Jaber, M.A., Porter, S.R., Gilthrope, M.S., Bedi, R. and Scully, C. (1999) Risk Factors for Oral Epithelial Dysplasia-The Role of Smoking and Alcohol. Oral Oncology, 35, 151-156. https://doi.org/10.1016/S1368-8375(98)00106-7

[29] Neville, B.W. and Day, T.A. (2002) Oral Cancer and Prcancerous Lesions. $C A$ : $A$ 
Cancer Journal for Clinicians, 52, 195-215. https://doi.org/10.3322/canjclin.52.4.195

[30] Brocklehurst, P., Kujan, O., O’Malley, L.A., Ogden, G., Shepherd, S. and Glenny, A.M. (2013) Screening Programmes for the Early Detection and Prevention of Oral Cancer. The Cochrane Database of Systematic Reviews, 19, CD004150. https://doi.org/10.1002/14651858.CD004150.pub4

[31] Dodd, J.V. (2015) Existing Screening Methods for Oral Cancer Are Generally Acceptable to Patients in Non-Dental Setting. Journal of Evidence-Based Dental Practice, 15, 61-66. https://doi.org/10.1016/j.jebdp.2015.03.011

[32] Seoane Lestón, J. and Diz Dios, P. (2010) Diagnostic Clinical Aids in Oral Cancer. Oral Oncology, 46, 418-422. https://doi.org/10.1016/j.oraloncology.2010.03.006

[33] Law, C.P., Chandra, R.V., Hoang, J.K. and Phal, P.M. (2011) Imaging the Oral Cavity: Key Concepts for the Radiologist. The British Journal of Radiology, 84, 944-957.

[34] Cancela Rodríguez, P., CereroLapiedra, R., Esparza Gómez, G., Llamas-Martínez, S. and Warnakulasuriya, S. (2011) The Use of Toluidine Blue in the Detection of Pre Malignant and Malignant Oral Lesions. Journal of Oral Pathology \& Medicine, 40, 300-304. https://doi.org/10.1111/j.1600-0714.2010.00985.x

[35] Shin, D., Vigneswaran, N., Gillenwater, A. and Richards-Kortum, R. (2010) Advances in Fluorescence Imaging Techniques to Detect Oral Cancer and Its Precursors. Future Oncology, 6, 1143-1154. https://doi.org/10.2217/fon.10.79

[36] Christian, D.C. (2002) Computer Assisted Analysis of Oral Brush Biopsies at an Oral Cancer Screening Program. The Journal of the American Dental Association, 133, 357-362. https://doi.org/10.14219/jada.archive.2002.0175

[37] Morrison, A.S. (1992) Introduction. In: Screening in Chronic Disease, 2nd Edition, Oxford University Press, New York, 3-20.

[38] Black, W.C., Haggstrom, D.A. and Welch, G.H. (2002) All-Cause Mortality in Randomized Trials of Cancer Screening. Journal of the National Cancer Institute, 94, 167-173. https://doi.org/10.1093/jnci/94.3.167

[39] Läära, E., Day, N.E. and Hakama, M. (1988) Trends in Mortality in the Nordic Countries: Association with Organised Screening Programmes. The Lancet, 1, 1247-1249.

[40] Tabár, L., Fagenberg, G., Gad, A., Baldetorp, L., Holmberg, L.H., Gröntoft, O., Ljungquist, U., Lundström, B., Månson, J.C., Eklund, G., et al. (1985) Reduction in Mortality from Breast Cancer after Mass Screening with Mammography. Randomized Trial from the Breast Cancer Screening Working Group of the Swedish National Board of Health and Welfare. The Lancet, 1, 829-832.

[41] Mandel, J.S., Bond, J.H. and Church, T.R. (1993) Reduction of Mortality from Colorectal Cancer by Screening for Faecal Occult Blood. The New England Journal of Medicine, 329, 1365-1371. https://doi.org/10.1056/NEJM199305133281901

[42] Ramadas, K., Sankaranarayanan, R., Binu, J.J., Thomas, G., Somanathan, T., Mahé, C., Pandey, M., et al. (2003) Interim Results from a Cluster Randomized Controlled Oral Cancer Screening Trial in Kerala, India. Oral Oncology, 39, 580-588.

[43] Sankaranarayanan, R., Ramadas, K., Thomas, G., Muwonge, R., Thara, S., Mathew, B., Rajan, B. and Trivandrum Oral Cancer, Screening Study Group (2005) Effect of Screening on Oral Cancer Mortality in Kerala, India: A Cluster-Randomised Controlled Trial. The Lancet, 365, 1927-1933. https://doi.org/10.1016/S0140-6736(05)66658-5

[44] Downer, M.C., Moles, D.R., Palmer, S. and Speight, P.M. (2006) A Systematic Review of Measures of Effectiveness in Screening for Oral Cancer and Precancer. Oral 
Oncology, 42, 551-560. https://doi.org/10.1016/j.oraloncology.2005.08.006

[45] Rethman, M.P., Carpenter, W. and Cohen, E.E.J. (2010) Evidence-Based Clinical Recommendations Regarding Screening for Oral Squamous Cell Carcinomas. The Journal of the American Dental Association, 141, 509-520. https://doi.org/10.14219/jada.archive.2010.0223

[46] Speight, P.M., Downer, M.C. and Zakrzewska, J. (1993) Screening for Oral Cancer and Precancer. Community Dental Health, 10, 1-89.

[47] Speight, P.M. and Warnakulasuriya, S. (2010) Evaluation of Screening for Oral Cancer against National Screening Committee Criteria. UK National Screening Committee Publications. http://www.screening.nhs.uk/oralcancer

[48] Moyer, V.A. (2014) Screening for Oral Cancer: U.S. Preventive Services Task Force Recommendation Statement. Annals of Internal Medicine, 160, 55-60.

[49] Kujan, O., Glenny, A.M., Duxbury, J., Thakker, N. and Sloan, P. (2005) Evaluation of Screening Strategies for Improving Oral Cancer Mortality: A Cochrane Systematic Review. Journal of Dental Education, 69, 255-265.

[50] Lim, K., Moles, D.R., Downer, M.C. and Speight, P.M. (2003) Opportunistic Screening for Oral Cancer and Precancer in General Dental Practice: Results of a Demonstration Study. British Dental Journal, 194, 497-502. https://doi.org/10.1038/sj.bdj.4810069

[51] Langevin, S.M., Michaud, D.S., Eliot, M., Peters, E.S., McClean, M.D. and Kelsey, K.T. (2012) Regular Dental Visits Are Associated with Earlier Stage at Diagnosis for Oral and Pharyngeal Cancer. Cancer Causes Control, 23, 1821-1829. https://doi.org/10.1007/s10552-012-0061-4

[52] McGurk, M. and Scott, S.E. (2010) The Reality of Identifying Early Oral Cancer in the General Dental Practice. British Dental Journal, 208, 347-351.

https://doi.org/10.1038/sj.bdj.2010.345

[53] Conway, D.I., Petticrew, M. and Marlborough, H. (2008) Socioeconomic Inequalities and Oral Cancer Risk: A Systematic Review and Meta-Analysis of Case-Control Studies. International Journal of Cancer, 122, 2811-2819.

[54] Marmot, M. (2005) Social Determinants of Health Inequalities. The Lancet, 365, 1099-1104. https://doi.org/10.1016/S0140-6736(05)74234-3

[55] Wade, J., Smith, H., Hankins, M. and Llewellyn, C. (2010) Conducting Oral Examinations for Cancer in General Practice: What Are the Barriers? Family Practice, 27, 77-84.

[56] LeHew, C.W., Epstein, J.B., Koerber, A., Goben, A., Reitmajer, K., Sroussi, H., Kaste, L.M., et al. (2002) Training in the Primary Prevention and Early Detection of Oral Cancer: Pilot Study of Its Impact on Clinicians' Perceptions and Intentions. Ear, Nose \& Throat Journal, 88, 748-753.

[57] Peacock, Z.S., Pogrel, M.A. and Schmidt, B.L. (2008) Exploring the Reasons for Delay in Treatment of Oral Cancer. The Journal of the American Dental Association, 139, 1346-1352. https://doi.org/10.14219/jada.archive.2008.0046

[58] Gómez, I., Warnakulasuriya, S., Varela-Centelles, P.I., López-Jornet, P., Suárez-Cunqueiro, M., Diz-Dios, P. and Seoane, J. (2010) Is Early Diagnosis of Oral Cancer a Feasible Objective? Who Is to Blame for Diagnostic Delay? Oral Diseases, 16, 333-342.

[59] Van der Waal, I., deBree, R., BraGoben, A., Reitmajer, K., Sroussi, H., Kaste, L.M., Kenhoff, R., et al. (2011) Early Diagnosis in Primary oral Cancer: Is It Possible? Medicina Oral, Patologia Oral Y Cirugia Bucal, 16, 300-305. 
[60] Ismail, A.I., Jedele, J.M., Lim, S. and Tellez, Mt. (2012) A Marketing Campaign to Promote Screening for Oral Cancer. The Journal of the American Dental Association, 143, e57-e66. https://doi.org/10.14219/jada.archive.2012.0328

[61] Awojobi, O., Suzanne, E.S. and Newton, T. (2012) Patients' Perceptions of Oral Cancer Screening in Dental Practice: A Cross-Sectional Study. BMC Oral Health, $12,55$.

[62] Kongevinas, M., Pearce, N., Susser, M. and Boffeta, P. (1997) Social Inequities and Cancer. IARC Sci. Publ., Lyon, 138.

[63] Warnakulasuriya, S. (2009) Significant Oral Cancer Risk Associated with Low Socioeconomic Status. Evidence-Based Dentistry, 10, 4-5.

[64] Allam, E. and Windsor, J.L. (2008) Social and Behavioural Determinants of Oral Cancer. Dentistry, 4, 182-184.

[65] Kujan, O.B. (2013) What Dentists Should Know about Oral Cancer Screening? European Journal of General Dentistry, 2, 229-234.

[66] Anandani, C., Metgud, R., Ramesh, G. and Singh, K. (2015) Awareness of General Dental Practitioners about Oral Screening and Biopsy Procedures. Oral Health \& Preventive Dentistry, 13, 523-523.

[67] Walsh, M.M., Rankin, K.V. and Silverman Jr., S. (2013) Influence of Continuing Education on Dental Hygienists' Knowledge and Behaviour-Related to Oral Cancer Screening and Tobacco Cessation. Journal of Dental Hygiene, 87, 95-105.

[68] Ebstein, J.B., Gorsky, M. and Cabay, R.J. (2008) Screening for and Diagnosis of Oral Premalignant Lesions and Oropharyngeal Squamous Cell Carcinoma. Role of Primary Care Physicians. Canadian Family Physician, 54, 870-875.

[69] Crossman, T., Warburton, F. and Richards, M.A. (2016) Role of General Practice in the Diagnosis of Oral Cancer. British Journal of Oral and Maxillofacial Surgery, 54, 208-212.

[70] Bánóczy, J., Bakó, A., Kósa, Z., Dombi, C., Ember, I., Kósa, Z., Sándor, J. and Szabó, G. (2001) Stomato-Oncological Screening: Is Early Diagnosis Possible. Magyar Onkologia, 45, 143-148.

[71] Németh, Z., Szabó, G. and Bogdán, S. (2010) Prevention and Screening of Oral Tumors. Hippocrates, 1, 52-55.

[72] Daley, E., DeBate, R., Dodd, V., Dyer, K., Fuhrmann, H., Helmy, H. and Smith, S.A. (2011) Exploring Awareness, Attitudes, and Perceived Role among Oral Health Providers Regarding HPV-Related Oral Cancers. Journal of Public Health Dentistry, 71, 136-142. https://doi.org/10.1111/j.1752-7325.2011.00212.x 